\title{
Miguel Cané: la escritura como fracaso ejemplar*
}

\author{
Miguel Cané: Writing As An Exemplary Failure
}

Juan Pablo Canala**

\section{RESUMEN}

Este artículo indaga en la escritura novelística desconocida de Palabras clave: Miguel Cané a partir de los papeles inéditos conservados en su archivo personal. La tensión entre las novelas escritas, pero jamás publicadas, y los pocos textos fragmentarios permiten complejizar la escritura de Cané y su figura como escritor y árbitro Miguel Cané, novela, crítica genética, archivo, escritura. cultural. La evidencia material que da el archivo permite volver a pensar una concepción de autor y de obra sensiblemente más rica que la clásica caracterización de los escritos de Cané.

\begin{abstract}
This article proposes a study of the little-known writings of Miguel Cané. The tension between the written and never published novels and his known fragmentary texts makes it possible to change Cané's figure as a writer and cultural referee. The archive's material evidence makes it possible to rethink a conception of author and work, richer than Cané's writings' classic characterization.
\end{abstract} Keywords: Miguel Cané, Novel, Genetic criticism, Archive, Creative process.

\footnotetext{
* Una primera versión de este trabajo recibió los amables comentarios de Alejandra Laera, Juan Pablo Dabove, Laura Cabezas y Elena Donato. Agradezco a Graciela Goldchluk sus invalorables aportes acerca de las problemáticas alrededor de los archivos personales, archivos de escritor y sus valiosas recomendaciones bibliográficas. El artículo deriva de una amplia línea de investigación del autor.

** Argentino. Doctorando de la Universidad de Buenos Aires, área Literatura. Becario doctoral de la Universidad de Buenos Aires con sede en Programa de Estudios de Historia Social y Económica (PEHESA) del Instituto de Historia Argentina y Americana “Dr. Emilio Ravignani" (UBA-Conicet), Buenos Aires, Argentina. sanchocuarto@yahoo.com.
} 


\section{El archivo como perspectiva}

Es posible que la nueva (vieja) literatura argentina ya esté escrita, vale decir, que haya una literatura que todavía no hemos leído y que sin embargo está al alcance de cualquier investigador desde hace mucho tiempo. Esa literatura que habita en los anaqueles de archivos y bibliotecas nos permite revisar - a la luz de esos nuevos materiales-, lecturas y concepciones heredadas acerca de textos y autores canónicos. La aparición de documentos inéditos o borradores desconocidos excede el hallazgo como hecho fortuito y permite volver a las obras, interrogándolas desde la materialidad de lo que ha podido conservarse en el archivo.

En un contexto en el que está cobrando relevancia el "giro material", como lo ha planteado Ezequiel Saferstein (144), los estudios literarios se están abriendo a las directrices y marcos teóricos propuestos desde otras disciplinas, que complejizan toda lectura crítica que atienda a la escritura, producción y circulación de los textos literarios, poniendo el acento en lo que Roger Chartier ha llamado materialidad del texto ("Materialidad del..." 8). En lo que concierne a los manuscritos de autor, el impacto tanto teórico como metodológico que implicó la reflexión en torno a los archivos resulta decisiva para complejizar la mirada en torno al objeto literario. Los archivos públicos, donde los textos son sometidos al rigor clasificatorio y al ordenamiento institucional, requieren ser interrogados no desde una concepción burocrática del archivo, sino a partir de un movimiento donde es posible encontrar una escritura viva, tal como la definió Louis Hay, que busque "desentrañar las redes de sentido de un manuscrito particular" ("La escritura..." 18).

Reclamar para los archivos la vitalidad de los discursos sociales que se inscriben en su materialidad, supone pensar una concepción dinámica de la escritura que preste atención a los procesos de génesis evidenciables en los manuscritos de autor. En ese sentido el marco teórico indispensable para recuperar esa literatura es el que propone la crítica genética que, en las más actuales revisiones de sus postulados teóricos, ha ampliado la definición misma del concepto de manuscrito, al pensarlo también como un conjunto archivístico:

El manuscrito no es la preparación del texto; no es lo mismo, pero sin terminar, sino que es un otro. Lo que se disuelve en esta distinción es la relación de causalidad y lo que se incorpora no son 
únicamente manuscritos, sino una constelación documental cuya forma es la del archivo. Leer a partir del archivo implica, de ese modo, romper la linealidad y atender a relaciones múltiples. (Goldchluk 60-61)

Asumiendo las perspectivas que hemos enunciado $-\mathrm{y}$ bajo la reflexión que impone la crítica literaria a las nociones de archivo y materialidad de los textos-, nos propusimos interrogar la escritura del autor, diplomático y político argentino Miguel Cané (1851-1905), a partir del conjunto de papeles de su archivo personal custodiado en la Sala X del Archivo General de la Nación (Argentina). Las quince cajas de documentos escritos que conforman este archivo ingresaron a esa institución por medio de la donación de uno de los descendientes del autor, el 19 de noviembre de $1969^{1}$. De ese profuso (y desconocido) conjunto de papeles, el trabajo que aquí proponemos se circunscribe a sus notas y borradores personales (ensayos de escritura y reflexiones autobiográficas), como así también a tres novelas inéditas allí conservadas. Desde el marco teórico enunciado, el presente estudio buscó problematizar, a la luz de los papeles inéditos de Cané, en algunas reflexiones acerca de su proceso escritural, que revelan zonas ignoradas de su producción escrita. Nos interesó dar cuenta de cómo esos papeles producidos, reunidos y atesorados nos permitían complejizar su figura de autor y de obra. Asimismo, advertimos cómo en sus borradores autobiográficos el autor inscribe textualmente su angustia por el acto de escribir y de qué manera, en lo que respecta a las novelas inéditas, el hecho de optar por mantener inéditos esos textos narrativos, dialoga con las posiciones de Cané en el contexto de las polémicas estéticas e ideológicas alrededor de la novela argentina durante la década de 1880.

\section{Angustias frente al papel}

En una pequeña libreta manuscrita, Cané ensayó su angustia ante el acto de escribir y, a juzgar por la apretada grafía que puebla las esque-

1 'El ingreso fue ratificado por decreto 2.651/69' y en su contenido se encuentran 'cuadernillos de notas; programas de su cátedra en la Facultad de Filosofía y Letras; cuentas liquidadas por las ventas de Juvenilia y por su traducción del Enrique IV; y borradores de producciones literarias, incluyendo los de su obra más famosa. Cané conservaba también los comentarios aparecidos en la prensa nacional y extranjera sobre sus trabajos"' (Archivo General de la Nación 116). 
las que la conforman, se podría advertir cierto nerviosismo con el que el autor se enfrenta al hecho de iniciar la escritura. En esa libreta se presenta, casi a modo de invocación, el testimonio acerca del trance que supone la puesta en marcha del trabajo del escritor: "Tengo que escribir sobre algo. ¡Fatal algo!” (Cané, Libreta 1).

La puesta por escrito de ese imperativo conjura las resistencias que se imponen a esa tarea y que, lejos de inspirar la calma, tienden a alimentar los temperamentos más álgidos. Así, esa tensión inicial se repliega sobre el objeto inanimado que el escritor sostiene en su mano:

Dejémonos de tonteras y vamos pluma, escribe lo que se venga a mi mente. Cual rápida centella que atraviesa los espacios y va a perderse en las entrañas de la tierra, para producir en ellas el fuego consumidor de los novelones (esta opinión es enteramente mía) que arrastra tras su ardiente lava cuanto cuerpo se presenta en su curso fogoso, tal así acaba de pasar por mi imaginación la idea de escribir sobre la Guerra del Paraguay, los ministros, los brasileros, la prensa, temas todos que son tan nuevecitos que no los tomo por temor de recibir una paliza. (Libreta 1 )

¿Sobre qué escribir? ¿Lo desconocido? ¿O sobre aquello que resulta cercano, vital y temporalmente? Esas preguntas circundan las anotaciones de Cané y, en los trazos que va dejando como testimonio en el papel, queda plasmada la angustia ante la falta de una idea, ante la soledad que experimenta un escritor enfrentando el blanco de la hoja y la indecisión acerca de aquello que aspira poner por escrito.

Recurrente en su estrategia, interpela a sus instrumentos de trabajo, plasma un diálogo imaginario con uno primero, con otro después:

- ¿Vamos a ver qué tal eres pluma?

Mala

$-i Y$ tú?

-Yo soy mejor, más no soy muy buena. (Libreta 1 )

Estas anotaciones dispersas, escritas en una libreta pequeña llena de ideas, dibujos y poemas, que en su caótica organización plasman las aspiraciones literarias del joven patricio, son también la evidencia del titubeo y la tensión que Cané mantenía con el acto mismo de la 
escritura. Escribir algo, lo que sea, de forma rápida. Angustia por el tiempo, por el tema o por el género. El deseo de poder escribir esos novelones, esos tan mentados textos extensos, alterna con el horror vacui de no poder concentrarse en producir algo. Así, la escritura se reduce a pura técnica y lo sobresaliente de estos textos no es el carácter germinal de una escritura futura, sino más bien la escritura como gesto autorreferencial: en palabras de Roland Barthes, la escritura que "se separa apenas de su función instrumental y solo se mira a sí misma" (14). Escribir para poder demostrar, mientras se escribe, acerca de la imposibilidad de la propia escritura se vuelve una constante en los bordes y márgenes de los cientos de papeles dispersos que conserva el archivo del escritor.

Para Harold Bloom, la angustia es un sentimiento que impulsa hacia adelante, construyendo una cadena edípica con la tradición (1617). No obstante, cabría señalar que la escritura, como vemos a través de múltiples testimonios y como ha establecido la crítica genética, se presenta como discontinua, recurrente y atravesada por fuerzas heterogéneas que responden a temporalidades diversas, donde se presentan lógicas inconciliables, dejando huellas en cualquier escritura que sea examinada con detenimiento. Incorporar el cuerpo material de una escritura pondría en crisis esa cadena de eventuales identificaciones que propone el modelo edípico, porque la angustia no solo debe ser pensada en relación con una eventual influencia, sino que debe ser entendida también como inherente al cuerpo del escritor. Como ha planteado Sara Ahmed "la sensación de miedo nos presiona hacia ese futuro como una experiencia corporal intensa en el presente" (109); así, la angustia y el miedo de la escritura por venir modela tanto el cuerpo del texto de Cané, como también su cuerpo escribiente. Lejos de ser un sentimiento movilizador, la angustia paraliza al presentarse como un temor inespecífico que corta el flujo del deseo. El deseo atravesado por la angustia se convierte en una especie de opresión del cuerpo. En la escritura de Cané, en el cuerpo de su escritura, se inscriben marcas que permiten leer no solo su producción, sino también nuevas relaciones con la escritura de su entorno.

Cané, de forma recurrente y compulsiva, dedica varios escritos a exponer su crisis creativa, a lamentarse por la ausencia de una ruta que lo guíe, que lo ayude a terminar sus textos. A su vez, los escritos de esa 
libreta dejan entrever la conciencia de otro actor determinante en el circuito del hecho creativo: el público. En esa misma página Cané escribe: "El desocupado lea, el crítico muerda" (Libreta 1) con esta frase cifra una de las principales cuestiones desde donde habría que pensar a la literatura de Cané, donde no solo la escritura es puesta en escena como problemática, sino también como la tensión entre escribir y dar a conocer a otro(s) aquello que se escribe. Sus originales de escritura hacen visible, de forma dramática, el dilema entre escribir y publicar, que a su vez conlleva otros: elegir qué escribir y decidir finalmente qué publicar de todo lo escrito.

La evocación de esos "novelones" presupone aquello que era central para todo aspirante a un trabajo de escritura durante la década del 1880, es decir, aquello que la efectiva ejecución de un proyecto literario debía enfrentar: la cuestión de la novela nacional como aquella que constituye un "proceso complejo de formación de opinión pública y de construcción de imaginarios sociales (...) un espacio de crítica de la sociedad y, a la vez, de representación de los conflictos reales (Espósito 15). Según ha caracterizado Alejandra Laera (31-71) el camino obligado para todo aquel que pretendiera ser un novelista traía aparejada, tanto la renuncia a la actividad pública (sea política o militar) como la fuerte vinculación entre tiempo de escritura y capital económico. En este contexto serán Eugenio Cambaceres y Eduardo Gutiérrez aquellos que sintetizarán las dos vías posibles de concreción de la figura del novelista en la década del 1880. Entre el escritor amateur que vive de rentas y el escritor profesional que vende su producción, se diseña para la literatura argentina la emergencia del novelista.

Ahora bien, cabría preguntarse: ¿qué lugar ocupa la concepción que Cané tenía de la novela respecto de sus contemporáneos? Su situación resulta sensiblemente diferente, puesto que su escritura no se libraba por fuera de sus actividades estatales, gestándose en el margen del ocio que dejaba su rol como diplomático. Sin embargo, esa escritura, alejada de la arena de la prensa y del tiempo ocioso del rentier, exhibe una red de tensiones originarias que modelarán tanto sus obras, como el destino que tendrán. La pregunta que subyace a la lectura de la obra de Cané que aquí proponemos presupone dos cuestiones. Por un lado, la explicitación continua de sus concepciones acerca de la novela y la adopción de la autobiografía como género frente al avance 
disolvente que connotaba el naturalismo y las ficciones populares en la Argentina de ese período. Por otro lado, el eminente lugar como "árbitro cultural" (Pastormerlo, "Miguel Cané..." 272) y representante de una ideología del patriciado porteño (con sus concretas convicciones morales y estéticas), ese lugar preponderante, ese espacio que como crítico ocupa, sobrevolará la propia tarea de su escritura, ocasionando una particular relación de Cané con su propia producción, aspecto que incidirá de forma decisiva en la determinación de publicar o no sus textos, entre los que se cuentan, no sin llamativa particularidad, algunas novelas. ¿Por qué no dar a conocer esos tan anhelados textos luego del trabajo que implicó el haberlos escrito? ¿Cómo se inscribe su concepción acerca del ideal de la novela en el marco del debate alrededor de la ficción nacional?

\section{El crítico lector}

En un temprano artículo titulado "Después de una lectura" (1877), Cané anunciaba sus primeras observaciones en torno a la novela. La añoranza que expresa por la figura de Alexandre Dumas - anticipando lo que en 1884 dirá de esos folletines en Juvenilia- o de Honoré de Balzac se contrapone con el desdén que tiene respecto del avance de la escritura de los autores naturalistas: "La corriente se acentúa más y más; el estudio del alma cede el campo a la fisiología y esta a su vez abandona la partida a la infecta manera de los señores Goncourt y Zola, que, bajo pretexto de hacernos odiar el vicio, nos sumergen en los antros infames donde desaparece por siempre la dignidad humana" (Charlas... 227). Así, posicionado desde un lugar crítico de los eminentes naturalistas franceses, la novela debe ser un género rico en estilo y en sencillez. Para nada, advierte Cané, el género debe perseguir una búsqueda de algo que no sea el esparcimiento y la distracción: "Busco un elemento de olvido, un calmante para excitación de mis nervios, una fórmula que contenga la cantidad de atracción suficiente para sustraerme a dolorosas preocupaciones" (Charlas... 227).

Si bien este pequeño ensayo está fechado a fines de la década de 1870, Cané opta por incluirlo en una recopilación publicada ocho años más tarde bajo el título de Charlas literarias (1885). La reaparición de este pequeño ensayo, reivindicatorio del estilo animado y jovial que debe tener la novela en oposición al naturalismo, plantea algunas 
cuestiones fundamentales para entender qué tipo de intervención está realizando Cané respecto del debate alrededor de la novela nacional. La doble temporalidad del ensayo (1877 y 1885) supone dos contextos de enunciación diferenciados. Si en 1877 advertía del carácter liviano de la novela y del lugar subsidiario que mantenía en relación con otros géneros como la historia y la filosofía, su nueva publicación en 1885 supone dos cosas. En primer lugar, la certeza para Cané de que es en la lectura de folletines como los de Dumas donde se concretaba ese imperativo de evasión y esparcimiento, y, en segundo término, intervenir en la discusión contra el naturalismo en el contexto del éxito escandaloso de las dos primeras novelas de Cambaceres.

La opción pública de Cané resulta de un posicionamiento respecto del estilo dominante de la novela argentina de 1880 . Un género narrativo donde no se buscaba una identidad de cohesión, sino más bien lo contrario, como afirma Laera (39). Será entonces en las memorias o en las autobiografías donde se presentaría esa unión y cohesión nacional que desbarata la novela. Es interesante que la actitud que toma Cané frente a la escritura de la novela sea similar al prejuicio ideológico y el lugar que tuvo su figura como "administrador cultural". Tal es así que en sus memorias, Manuel Gálvez dirá: "era en nuestro ambiente algo como lo que Anatole France en París" (82). La centralidad de su figura lo convirtió en un autor muy celebrado, pero esa figura de "administrador cultural" también está presente en muchos de los juicios que el propio autor hizo respecto de los jóvenes: "Un elogio de Cané consagraba realmente a un escritor cualquiera (...) sobre todo si el elogio lo hacía desde las columnas de un gran diario", dice Gálvez, y continúa: "Hay en nuestro país, fácilmente, treinta escritores que han realizado una obra de mayor vastedad y vigor que la de Cané; pero ninguno tiene en la sociedad el prestigio que él tuvo. No me refiero a la fama que había adquirido por Juvenilia y por su prosa, sino a lo que pesaba una opinión suya" (99).

Las afirmaciones de Gálvez dejan entrever algunas cuestiones nodales para comprender el proceso de formación del incipiente campo intelectual y del mercado de bienes culturales en la Argentina en el arco que va desde 1880 al entresiglo. En primera instancia la certeza de que la prensa funcionaba como la administradora de los bienes culturales, ya fuera porque permitía o auspiciaba la circulación de textos literarios (en forma de folletines o de adelantos de libros), o bien, por- 
que brindó el espacio para la emergencia de la figura del crítico. En ese sentido Cané, que tanto denostaba el embrutecimiento de la escritura en los diarios, se convirtió en una eminente figura que podía impulsar o hacer naufragar a aquellos que intentan hacerse de un lugar y de un nombre en la prensa de la época. Y es en este otro sentido, el del nombre de autor y la constitución de una obra, donde la evocación de Gálvez deja en claro que el peso de la opinión de Cané se asienta más en la prepotencia de su nombre y en la fama adquirida por un prestigio de clase, que en el conjunto de textos que constituyen su obra. De modo que es el nombre propio, como sinécdoque de su prestigio, lo que ocupa el primer plano frente a la propia producción de autor. En ese punto, era más por el respeto, la trayectoria y el nombre, que por aquello que había escrito.

De este modo, y con el concreto lugar que irá ocupando, resulta sintomático el posicionamiento de Cané frente a las dos alternativas posibles en el proceso de emergencia de la novela argentina durante el ochenta. Esto es: en primer lugar, la novela naturalista (que ya había desarrollado una larga descendencia de sus formas a partir de la traducción y circulación del género en el Río de la Plata) y, por otro lado, la novela popular en folletín. La tensa relación que Cané mantuvo con estas expresiones del género novelístico vendría dada por el lugar del patricio como lector de ficciones de sus compañeros de clase, y sobre eso se pronunciará, aunque de forma divergente.

Por otra parte, si algo resulta característico, en el caso particular de la obra de Cambaceres, es la continua y sistemática escritura de reseñas. Cané fue un lector detallista de Potpourri, de Música sentimental, de Sin rumbo y sus intervenciones como crítico lector encontraron su espacio de difusión en el marco del diario portavoz de la élite porteña: Sud-América ${ }^{2}$. No es menor que estos textos apare-

2 Sobre el funcionamiento político del diario sostiene Tim Duncan: “El diario no sólo el portavoz sino también el foro de su facción política. Un artículo requería la aprobación de los varios comités editoriales antes de su publicación; si una idea era considerada suficientemente buena, se la repetía hasta que llegase a ser un punto central de una nueva línea política. Sud-América se desempeñó así respecto de los juaristas cuando los seguidores del presidente evaluaban las implicancias del continuo alejamiento entre éste y Roca, su mentor. Interpretaciones claras y razonables de las ideas juaristas sobre la República y sobre su propio lugar en el destino de aquélla, empezaron a aparecer regularmente durante 1888. El estilo del diario cambió radicalmente. Sutileza, persuasión, esperanza y razón llenaron columnas que habían tenido poco tiempo atrás un cariz to- 
cieran en el folletín de este diario y ante la vista de otros miembros conocidos de la sociedad porteña, porque esa tensión del lugar de enunciación, bajo la mirada de otros miembros de su círculo, se traslucirá en el posicionamiento que el escritor mantuvo respecto de los libros de quienes fueron sus amigos más próximos. Escrito durante su estadía diplomática en Viena, el texto de Cané a propósito de $M u ́$ sica sentimental es ambiguo:

Detestable, deplorable, odiosa. Eso no es literatura, eso no es arte, eso es simplemente un parti pris inexorable, un despilfarro de talento, un capricho de patricio que hace tapizar sus letrinas con telas de Persia. La naturaleza no nos ha dado la facultad de reproducir el color y la forma de las cosas para que las empleemos en pintar amorosamente las úlceras de un perro o esculpir la cabeza deforme de un enano (...) Toda la escuela a que Música Sentimental pertenece, exagerada, violenta, torpe a veces, es un atentado no tanto contra la moral sino contra el buen gusto, la educación intelectual de la sociedad, tosca por naturaleza y que necesita el espectáculo constante de las cosas bellas para no caer en una degradación de forma y fondo que haría imposible la vida para el autor mismo como para todo hombre delicado. (Espósito et al. 131)

La crítica que realiza Cané a la segunda novela de Cambaceres es decisiva, y en ella resuena el eco de las ideas que gravitaron sobre aquel viejo ensayo escrito en 1877. Esta reseña (y otras) ponen de manifiesto las concepciones que Cané, en su rol de árbitro cultural, tiene respecto de lo que debe ser la novela nacional. ¿Debe el arte ocuparse de representar este tipo de vicios? La invectiva se dirige entonces a Cambaceres en cuanto a lo que debería ser lo representable, o al menos, lo que la postergada novela nacional debería representar. Y agrega: "Los que sabemos lo que cuesta escribir y pintar podremos tal vez apreciarla” (131).

Esta última afirmación revela cómo, hablando de Cambaceres, Cané expone su propia problemática en torno a la escritura. La escri-

talmente diferente. Sud-América nunca logró, sin embargo, reconciliar totalmente estos dos caracteres; el guerrero y el pensador podían muchas veces surgir de una misma pluma, pero uno al lado del otro en la misma página del diario provocaba la sensación de que el pensador era deshonesto y el guerrero un farsante. (767-768). 
tura cuesta y, será en esa confesión solapada, donde se haga presente la compleja relación entre técnica y tiempo. Si el escritor tiene tiempo y facilidad para la escritura - y desde su óptica, Cambaceres reuniría imaginariamente esas cualidades- ¿por qué no dedicarse a temas más interesantes, al ejercicio de estéticas moralmente aceptables? El dilema que instaura Cané en esta reseña escenifica la tensión entre las habilidades técnicas o materiales y el tema o ideal de realización de la novela. Reconoce en Cambaceres un escritor sobresaliente, y si bien le imputa que su éxito se debe a la decisión escandalosa de escribir una serie de novelas donde, bajo una estética reprobable como el naturalismo, se cuentan chismes de sociedad, de ninguna manera ignora que hay en el autor de Potpourri un estilo atrayente y vívido, un talento de escritor.

La justificación de por qué un talentoso miembro de su propia clase escribe ese tipo de novelas reaparece en la extensa reseña que le dedicará a Sin Rumbo, que más que un mero comentario, se trata de un texto retrospectivo que reconstruye la trayectoria literaria del novelista:

Enfermo, hastiado, Cambaceres, para distraerse, tomó un día la pluma y al correr, sin pretensión literaria, como si hablara con un amigo, en el mismo lenguaje familiar y criollo, escribió veinte páginas. Cuando miró el reloj, vio que había pasado bien un buen pedazo de tiempo. ¿Quién no vuelve a un remedio que alivia? Al día siguiente escribió otras veinte y al cabo de un mes tenía un volumen que tituló Silbidos de un vago. (Espósito et al. 144)

La escena de escritura recreada es el reverso de la angustia que testimonia la libreta personal de Cané. Al reconstruir imaginariamente la génesis de Potpourri se escenifican las razones por las que alguien de la clase y del talento de Cambaceres, pudo haberse entregado a ese tipo de escritura. Escribir rápido para paliar la angustia (también reverso de la lectura que sosiega, anunciada por Cané en su ensayo de fines de 1870), escribir para pasar el tiempo o para eludir el spleen. Pero la problemática no estaría focalizada en la escritura, sino en la intención de que ese acto liberador y catártico pase del dominio de lo privado e íntimo hacia lo público. Esto demuestra cómo Cané concibe la escritura (se invierte tiempo, se escribe por las razones que sean necesarias), pero no siempre todo lo que se escribe merece y debe ser publicado. 
Porque entre lo que se publica y lo que no, en esa autorregulación de la escritura, se fundaría la construcción del estilo y del escritor como figura pública. Esa doble inscripción aparece en la reseña cuando se marca la relación entre "obra" y "figura de autor":

Lo releía últimamente en viaje y no podía conformarme de ver a Cambaceres hacer artículos de diario largos en forma de libro, descuidados e incorrectos, cuando tengo la conciencia de que un poco de trabajo y un cambio de rumbo intelectual, le permitirían producir obras que serían orgullo para nuestras letras y gloria para él. No, en el fondo, a un hombre de su valor, no puede satisfacerle el éxito de mala ley de sus libros, esa reputación de sadismo que empieza a rodear su nombre. (Espósito et al. 145)

Al caracterizar el estilo de la novela homologándolo con el de los textos producidos en el marco de la prensa, Cané plantea una divisoria entre la escritura librada en el periodismo, frente a la escritura literaria: el ámbito del diario es el lugar donde la escritura sufre un embrutecimiento y una negación del estilo que debiera comportar un género como la novela. En este sentido, algunas de las afirmaciones y concepciones de Cané podrían encontrar su eco en lo que, por esos mismos años, también se vuelve un tema de debate en América Latina, tal como lo ha caracterizado Julio Ramos "la radical dependencia que tiene la literatura de la prensa en el fin del siglo" (130) de la que Cané es tan solo un módico y local defensor, dentro de la constelación transnacional de burócratas ilustrados que pregonaban la "voluntad de autonomía" de la literatura (137).

En las ficciones de Cambaceres hay valor en el estilo, es decir, en la técnica de la escritura, en el modo tan original con el que el escritor desarrolla ese trabajo e impone una estética: "El campo de observación es tan vasto y tan inexplorado entre nosotros, que me da una pena profunda ver a un hombre tan bien dotado, que es hoy un escritor completo (...) desviarse con deliberado propósito, pintar llagas inmundas ante una sociedad como la nuestra, la que más necesita la prédica incansable del ideal" (Espósito et al. 131).

De modo que la crítica más incisiva acerca de los textos de Cambaceres se da en la contradicción existente entre la articulación literaria y el tema elegido. Hay talento para la observación, pero no para 
la elección de aquello que debe narrarse, porque para Cané la novela debe responder al ideal, a ese estilo de escritura que debe transmitir un miembro de la élite, un hijo del patriciado argentino y que, en su caso particular, dicta para otros en el marco de las reseñas. Es por eso que la pregunta que subyace al planteo de Cané es evidente: ¿Por qué un escritor tan esmerado desperdicia su estilo en narrar esos temas tan poco decorosos? Hay en la escritura del otro (en las novelas que reseña) una admiración a esa capacidad de observación, a esa naturalidad de la escritura. En parte hay una evocación tensa del deseo y envidia respecto del estilo del otro, de ese estilo que no se tiene y que Cané juzga como inadecuado para alguien de su clase, pero que a la vez encarna en él cierta admiración, cierto anhelo de posesión. Cané advierte un talento y una efectividad, donde la novela de su compatriota provoca escándalos $^{3}$.

La evidencia de esa tensión está en la efectividad del talento de escritura que tiene Cambaceres como programa estético. Las cartas entre ambos dan habida cuenta de ese fenómeno. En una de ellas, Cambaceres, le dice:

Entiendo por naturalismo, estudio de la naturaleza humana, observación hasta los tuétanos. Agarrar un carácter, un alma, registrarla hasta los últimos repliegues, meterle el calador, sacarle todo, lo bueno como lo malo, lo puro, si es que se encuentra, y la podredumbre que encierra, haciéndola mover en el medio donde se agita, a impulsos de los latidos del corazón y no merced a un mecanismo más o menos complicado de ficelles, zamparle al público en la escena personajes de carne y hueso en vez de títeres rellenos de paja o de aserraduras (...) Hacer en una palabra verdad, verdad hasta la cuja como dice Ud. (...) Si las crudezas le repugnan, suprímalas. Ni Stendhal, ni Flaubert, ni Daudet, tres maîtres del género, las gastan. Si el calador le da asco, no se lo acerque a las narices; limítese a hacerlo circular por el auditorio, con el gesto fruncido y el brazo tieso. Si

3 Como sostiene Sergio Pastormerlo: "la irrupción del escándalo literario fue también el signo de una contradicción nueva entre literatura y moral de clase - es decir, de una inicial separación entre literatura y clase dominante. A mediados de la década de 1880 los letrados tradicionales debieron aprender con urgencia que el decoro y la "elevación moral” no eran atributos indispensables del arte." ("Novela, mercado... 25). 
el argot no es lengua de su paladar, no hable argot francés ni argot criollo, ni nada.

Pero eso sí, insisto en una cosa y es esta: no ponga almíbar en la boca de un changador, ni le haga decir mierda a una institutriz inglesa; respete la verdad. En cuanto a mí, Ud. sabe que tengo un flaco por mostrar las cosas en pelota y por hurgar lo que hiede; cuestión de gustos. (Cambaceres 3)

La respuesta de Cambaceres supone una auténtica lección de escritura. En el sentido que le muestra a Cané aquello que sería lo central de su poética, que de cierta forma rechaza la búsqueda de un tono, o de un ideal necesario que Cané seguirá reclamando para la novela. Cambaceres piensa la escritura novelística como el ámbito de la observación, como un tipo de dispositivo textual que contenga y trasmita a la narración una verdad. Análogamente, la otra vertiente de la novela argentina, la folletinesca y popular cultivada por Eduardo Gutiérrez, también aparece mencionada en una carta de Cané al Dr. Ernesto Quesada:

Después del ochenta, partí para el extranjero y, luego de una rápida gira por América, se me envió a Viena, donde no pudiendo ocuparme de política, ni de comercio, maté el tiempo escribiendo y publicando dos o tres librillos. Naturalmente, así que iban apareciendo, los enviaba con cariñosa dedicatoria a Eduardo Gutiérrez. En cambio, a pesar de que los diarios me habían informado de la aparición de Juan Moreira y alguno de sus otros congéneres, debido a la pluma de Eduardo nunca llegó a mis manos ninguno de ellos. En mi primer viaje a la tierra, allá por 1883, la primera vez que me encontré con Gutiérrez, le reproché amistosamente su falta de reciprocidad y le anuncié que pensaba comprar sus libros para leerlos en el viaje de regreso. Fue entonces cuando un poco ruborizado y tomándome la mano, me dijo textualmente: 'No le he mandado esos, porque no son para Ud. ni para la gente como Ud. Le ruego que no los lea, porque si lo hace me va a tratar muy mal. Yo le prometo a Ud. que así que esos abortos me aseguren dos o tres meses de pan, me pondré a la obra y escribiré algo que pueda presentar con la frente levantada a todos los hombres de pensamiento y de gusto. Dos o tres meses de pan, para aquel perfecto bohemio que nunca supo ni el valor del dinero, ni del tiempo, ni del trabajo, era 
un sueño lucuniano. Puesto en el yunque, en el yunque siguió hasta la muerte, dejando ese fárrago de folletines encuadernados, que no he leído, que no leeré jamás, porque son muy inferiores a lo que su autor valía, y pienso conservar de él solo el recuerdo de su espíritu fino y artístico. ("El criollismo" 236-237)

La imputación a la otra posibilidad de la novela argentina es la misma que para Cambaceres, por cuanto la literatura de Gutiérrez no se encontraría a la altura de una escritura que le haga justicia. La estrategia empleada en este comentario resulta interesante, puesto que construye la voz de Gutiérrez y coloca en su boca juicios adversos acerca de su propia obra. Pero si en relación con las novelas de Cambaceres había una continua y metódica lectura "intensiva” (Darnton 90) de sus novelas en las reseñas, para el caso de los folletines de Gutiérrez, la actitud se desplaza hacia una abstención voluntaria de leerlos. Estos posicionamientos, desde el lugar del crítico o del árbitro cultural, ese lugar simbólico en el incipiente campo intelectual durante 1880 habilita una relectura, desde la actuación pública, de los temores que se conjuraban en la libreta citada, al hacer visible la certeza de Cané (de alguna forma encarnada finalmente en él mismo) de que el crítico "muerde".

Así quedaría en evidencia, en la mirada de Cané, la no adscripción a ninguna de las formas posibles de la novela argentina del ochenta. Entonces ¿qué lugar ocupan las novelas escritas por Cané?

\section{La preparación de la novela}

La crítica ha coincidido en que la escritura de novelas por parte del autor de Juvenilia había redundado en auténticos fracasos. Particularmente se ha señalado lo que el propio escritor declaró en una nota al pie de una tríada de textos recopilados en su Prosa ligera (1901):

Este fragmento, así como los dos titulados 'De cepa criolla' y 'A las cuchillas, formaba parte de un estudio de nuestra sociabilidad en aquel momento, que empecé a escribir en 1884. Ese trabajo ha quedado definitivamente sin concluir porque esas cosas, cuando no se publican de primera intención, dan más trabajo para corregirlas, que para escribirlas de nuevo. Si publico aquí esos fragmentos es porque pueden leerse sin que choque su incoherencia, refiriéndose cada uno a un cuadro o asunto particular. (Prosa... 90) 
La escritura y la preparación de la novela parecería expresarse bajo la forma de la "novela inconclusa" o la "novela interrumpida", y en este sentido estos fragmentos dados a conocer son la punta del iceberg de un texto mucho más voluminoso que Cané escribió tentativamente a lo largo de dos años y que jamás vio la luz de forma completa. Esa novela, titulada Clara (c. 1883-1884) tiene, al igual que los fragmentos publicados, a Carlos Narbal como protagonista quien, al igual que los otros personajes de las ficciones inéditas de Cané, presenta un personaje arquetípico, una suerte de modélico "héroe patricio": taciturno, moralista, alejado de las tentaciones y de los vicios y con una redención fijada en la consumación del matrimonio. En Narbal (y otros héroes ficcionales) se materializan los valores que para Cané debería transmitir la novela nacional. En este sentido, el estilo de su novelística resulta diametralmente opuesto al que, por esos años, los lectores habían advertido en la obra de Cambaceres. Y si la crítica ha consensuado una identificación entre el vago que ventila chismes de sociedad en Potpourri y la propia figura del rentier despreocupado, se ha tendido a pensar que Narbal funciona análogamente en relación a la figura de Cané, entendiéndolo como alter-ego del propio autor ${ }^{4}$. Resultaría más interesante salir de las posibles identificaciones entre autor y personajes, para pensar a estos protagonistas de las novelas inéditas de Cané como la materialización literaria del tipo de héroe moral y arquetípico que, desde su perspectiva, funcionaría como el ideal de la ficción nacional. Contrariamente a los personajes adúlteros de Cambaceres, donde el matrimonio aparece para ser vituperado y puesto en discusión como institución, las novelas de Cané presentan de forma recurrente al matrimonio como dechado de virtudes y como revés de la vida licenciosa de la juventud. En ese sentido Cané evoca, en el contexto de otras experimentaciones de la novela alrededor del matrimonio ${ }^{5}$, la adopción de

4 Sergio Pastormerlo propone: "Carlos Narbal, un Miguel Cané mejorado con las adiciones de la educación inglesa, el dinero y el coraje militar, responde a esas preguntas en tanto tipificación de una aristocracia criolla de legitimidad justificada. Al escribir sobre Narbal, Cané volvió a escribir sobre sí mismo y como miembro de su clase: cada tanto olvidó la impersonalidad de la tercera persona y pasó a un 'nosotros' que lo incluía junto a sus lectores más cercanos" ("Miguel Cané" 268).

5 En este sentido Cané elude por completo la problematización que puede encontrarse en cierto recorte de la novela contemporánea entendida como "ficción somática", tal como lo ha formulado Gabriela Nouzielles, donde: "Entre las así llamadas 'novelas del inmigrante', hallamos dos ejemplos extremos de ese modelo narrativo, donde la refutación del romance fundacional adopta la forma de un mecanismo paranoico enloquecido 
un modelo regresivo, que en la literatura argentina puede encontrarse en las primeras manifestaciones románticas del género donde, como sostiene Doris Sommer: "La metáfora del matrimonio se desborda en una metonimia de consolidación nacional en el momento en que contemplamos sorprendidos cómo los matrimonios acortaron distancias regionales, económicas y partidistas" (35).

De igual manera, en estas ficciones, amor y matrimonio convergen y se necesitan: "La amaba con locura. El despertar sonriente del amor con el alma de Clara no podía compararse a la callada vehemencia que dominaba en absoluto el corazón sereno y el espíritu de Carlos" (Clara 88). Y agrega más adelante a propósito de los anhelos de Narbal: "Esperaba casarse, ser útil a los suyos" (89). De modo que el casamiento es una vía de utilidad en la formación del ciudadano patricio argentino y en esa misma tónica podría leerse un texto más breve y sin fecha titulado: La noche de la media luz (s/f), en el que se narran los sentimientos que atraviesan Carlos y Margarita en los momentos previos a la consumación del hecho carnal luego de una suntuosa fiesta de bodas. Resulta no menos interesante el punto de inflexión que supone en la biografía del protagonista del texto el momento de su casamiento:

Carlos estaba nervioso, enormemente sobresaltado: le irritaban las enigmáticas miradas de que era blanco la trémula Margarita (...) Dos horas hacía que se habían casado, doce las crueles, entregados inermes al análisis cáustico que es la base de las convenciones sociales (...) Carlos tenía veinte y seis años, su vida había sido agitada, pero de esa agitación brillante de la juventud. Todas las pasiones se habían desarrollado violentamente en él. Poseedor de una bella fortuna, había gastado sus rentas con viajes, fiestas, amores, duelos, placeres, todo lo había gozado: el mundo no era nuevo ya para él y al caer de la brillante región de las ilusiones encontró una buena y bella criatura a quien había amado con esa fuerza exquisita del corazón que en la época de la orgía y el bullicio duerme en el fondo del alma, como el misterioso germen de la felicidad futura. ( $L a$ noche 1-3)

que persigue insistente e incesantemente, en todos y cada uno de los niveles de la representación, a los extranjeros contaminados que supuestamente atentaban contra la salud de la familia argentina" (131). 
Entre sus papeles personales, Cané conservó otra novela fechada en 1890, y escrita en las hojas membretadas de la Delegación de la República Argentina, a la que tituló El vencedor. Su protagonista León Bartel sufre los desconsuelos de una relación amorosa trunca, cuando entre él y su amada Diana se interponen los deberes de madre de ella. En el último capítulo irrumpe una misiva:

A la carta acompañaba un retrato: el de un niño de dos o tres años, de facciones finas y delicadas con unos grandes ojos tristísimos que parecían implorar. Al pie del retrato, la mano del niño había sido guiada para trazar estas palabras: 'Ven mamá, si no me moriré'. Bartel acechó la lectura con un nudo en la garganta; se levantó, cerró la puerta, se echó en un sofá y sintió correr por su rostro, las dulces y olvidadas lágrimas que lentamente desahogaron su corazón. ( $E l$ vencedor 49)

Bartel comprende los deberes de la madre al lado de su hijo y estoicamente renuncia a su amor, proclamando - el narrador lo asegura al final de la novela - que el pequeño Marcelo es el verdadero vencedor: "Quebrado, deshecho, volvió a su casa. El retrato del pequeño Marcelo había quedado sobre su escritorio; lo tomó, lo contempló largamente, lo puso en un marco y escribió al pie: el vencedor" (El vencedor 50).

La actitud de Cané frente a la novela oscila entre no publicar o hacerlo de forma fragmentaria. Clara, pensada originalmente para ocupar el espacio del folletín del diario Sud-América, se da a conocer como tres apéndices cuasi autónomos dentro de una compilación de prosas variadas. Resulta interesante y paradójico que el escritor ejerza sobre la novela completa la selección de tres fragmentos para dar a conocer. De modo que, si la lógica de la escritura resalta lo fragmentario de los textos reunidos de Cané, a propósito de la novela la lógica es contraria, ya que sobre un texto completo el autor fragmenta. En ese sentido Cané le impone a la novela la lógica de sus volúmenes de textos dispersos, como si renunciara premeditadamente al estilo posible y visible, de acuerdo con su extensión, del texto novelístico por sobre el de los artículos. Esto supone optar por una lógica de lo discontinuo respecto de las novelas en su lógica continua. Acerca de esta distancia entre dos zonas reconocibles de su producción, existe una intuición aguda esbozada por Martín García Mérou en una carta personal: 
Ha sido para mí tanto más grato recibir las Charlas literarias cuanto que su publicación me da esperanzas de que siga usted mejor o del todo bueno. No necesito decirle que he leído con interés y esmero todos los artículos de esa interesante colección (...) Personalmente le diré que me habría gustado que en algunos pasajes hubiera suprimido las referencias a amigos especiales, a tipos que pertenecen a un círculo tan estrecho como el de Buenos Aires, y cuya aparición no puede comprenderse fuera de allí. Sus libros son tan bellos, merecen de tal manera salir del escenario pequeño de nuestra capital, que no vacilo en hacerle este comentario porque para los lectores que no son de los nuestros pasan inadvertidas muchas cosas que le hubiera sido fácil suprimir haciendo el libro más general, huyendo de las especialidades locales. Le hago esta observación porque al leer de un tirón las Charlas literarias ha resultado a mi vista de una manera tan decidida este detalle, que creo que para los que no conozcan a usted, no dejarían de llamarles la atención las constantes referencias a cosas íntimas o relacionadas con su persona. (...) ¿Y su novela? ¿Se acuerda de lo que le he dicho tantas veces en Caracas? Es allí donde debe usted concentrar sus fuerzas. Tiene usted ya todos los elementos y los tiene de sobra, ¡Qué obra tan bella hará usted, si se pone a la tarea, con ese estilo fluido y delicado, su experiencia de la vida y su conocimiento de los hombres! Recuerdo que a fines del año pasado me decía usted que estaba escribiendo una narración llamada Clara. ¿La ha terminado? Si la publica, no olvide que el primer ejemplar será profundamente agradecido. (García Mérou, 2)

Ese volumen jamás se publicó y en esa negativa por la novela se advierte un imperativo que rige la obra de Cané: se publica solo si se tiene la convicción de un estilo adecuado, si se tiene una certeza acerca de la calidad de esa escritura. Cané se podría considerar como un escritor demediado, como la convivencia tensa y secreta de dos escritores contrapuestos: el público, que habilitó esa denominación tempranamente acuñada por Ricardo Rojas de "prosista fragmentario" (493), y el secreto novelista de archivo, aquel cuya prosa ficcional existe en los papeles personales que sobrevivieron como testimonio de esa otra escritura. En ese punto, Cané fue entonces una suerte de "novelista de archivo". Esta clara escisión entre la escritura privada y la pública se materializa a través de un sentencia lanzada al pasar en una de las ya citadas re- 
señas a la obra de Cambaceres, donde se explicita por primera vez un imperativo de la escritura: "Cuando se publica un libro es para él [el público] si no el manuscrito bastaría” (Espósito et al. 131). Resulta verosímil que el conjunto de novelas que alberga todavía hoy su archivo personal, no haya estado a la altura de la escritura que Cané esperaba ofrecer a sus lectores, optando así por mantener su producción en la materialidad silenciosa del manuscrito. $Y$ en ese sentido resulta decisiva la intuición de David Viñas al titular el capítulo de su ensayo sobre Cané bajo la conjunción de "miedo y estilo" (217). Ese rótulo, que poco tiene que ver con el contenido del capítulo, condensa dos aspectos centrales del dilema estético que se le presenta al escritor. Cané renuncia a ser un novelista, opta por la autobiografía, guiado posiblemente por el "miedo", por el temor de que su escritura de novelas no esté a la altura del estilo, de ese ideal de escritura que le imputa como faltante a los exitosos Cambaceres y Gutiérrez, prefiriendo entonces ese estilo del entre nos que le objeta Martín García Mérou. Pero ¿hay lugar en la república de las letras para el ideal anacrónico de las novelas de Cané?, ¿cuánto incide esa imaginación novelesca como fundamento de ese silencio voluntario? Como afirma Jacques Rancière a propósito de la novela francesa decimonónica, el efecto democratizador de la novela pone en crisis los valores y convenciones heredadas. Así, los personajes imaginarios de las novelas naturalistas y de los folletines populares producen un nuevo real que "ya no es un campo de operación para los héroes aristocráticos de las grandes acciones o de los sentimientos exquisitos, sino el entrelazamiento de experiencias individuales, el tejido vivo de un mundo en el que ya no es posible distinguir entre las grandes almas" y "los individuos encerrados en la repetición de la vida desnuda" (26). En las novelas de Cané no hay inmigrantes deformes, ni patricios adúlteros, ni bandidos desaforados, su ideal de escritura no tiene lugar en el contexto de la novela contemporánea. Así, el miedo a la escritura, la angustia ante la hoja en blanco es también un límite estético, moral y político, que termina por condenar a esos originales de escritura ficcional a mantenerse inéditos.

\section{Coda}

En su libro Charlas literarias, Cané incluye un texto escrito en 1884 sobre la novela de Dickens: David Copperfield, allí puede leerse: “[el 
libro] pasa a mis ojos con todo fundamento por ser una autobiografía de Dickens. Y no me digan que es una ficción, porque ese tipo ha vivido, más aún, se ha llamado Carlos Dickens" (8-9). La figura de Copperfield, como modelo heroico de la novela; y la postulación de Dickens como un precursor elegido que logra fundir literatura y biografía, no deja de ser un efecto de lectura, una operación crítica de Cané como lector. Así, al leer desde allí esta novela, Cané postula la dualidad entre obra y vida, entre ficción y autobiografía, como una solución posible, como una escritura alternativa a la novela que les es contemporánea. La obra de Dickens reseñada se vuelve el fundamento que permite leer con mayor claridad el gesto de escritura presente en Juvenilia. Cané sortea el desafió que supone la construcción de un ideal ficcional, silencia a Narbal y a Bartel, los héroes de sus novelas, y se convierte él mismo en un personaje ejemplar en el marco de su autobiografía. Así, desplaza sus convicciones estéticas, morales y políticas de la ficción a la autobiografía, eludiendo los desafíos que sobrevuelan alrededor de la escritura novelística. Pero la vida ejemplar que puede leerse en la autobiografía de Cané es también la historia de un fracaso voluntario. Fracasar públicamente como novelista para triunfar como escritor público, como alguien que exhibe, por medio de la escritura de la propia vida, un espejo en el que la patria puede mirarse. El carácter moralizante y pedagógico que trasmite el tono de Juvenilia es la superación ensayada por Cané frente a los personajes de novela que avanzan contra los ideales de cierto sector de la clase dirigente.

La indagación de una escritura otra, no mostrada, no plausible de juicios ajenos y evaluaciones, es la que queda como evidencia material dentro del archivo y es también la que nos permite pensar que el silenciamiento deliberado de esos textos inéditos redimensiona las operaciones de construcción de Cané como autor y como figura pública. Leer desde el archivo, como nunca se había hecho antes, permite volver a pensar una concepción de autor y de obra sensiblemente más rica que la mera caracterización tradicional que la crítica tuvo acerca de la producción literaria de Cané, a la vez que nos revela a un escritor activo y sensible a los debates estéticos e ideológicos de su tiempo. 


\section{Referencias bibliográficas}

Ahmed, Sara. La política cultural de las emociones. Trad. Cecilia Olivares y Helena López González de Orduña. México D.F., Universidad Autónoma de México, 2015.

Archivo General de la Nación. Archivos y colecciones de procedencia privada, Comisiones especiales y homenajes. Sección documentación donada y adquirida (Sala VII). Buenos Aires, Ministerio del Interior, Obras Públicas y Vivienda, 2016.

Barthes, Roland. El grado cero de la escritura seguido de nuevos ensayos críticos. Trad. Nicolás Rosa. Buenos Aires, Siglo XXI, 2003.

Bloom, Harold. La angustia de las influencias. Trad. Francisco Rivera. Caracas, Monte Ávila, 1991.

Cambaceres, Eugenio. Carta a Miguel Cané. Buenos Aires, 1883.

Cané, Miguel. La noche de la media luz. Buenos Aires, (s/f). . Libreta. Buenos Aires, (s/f). . Clara. Buenos Aires, 1883. Charlas literarias. Sceaux, Imprenta de Charaire, 1885. . El vencedor. Paris, 1890.

Prosa ligera. Buenos Aires, Arnaldo Mohen, 1901. "El criollismo. Carta al Dr. Ernesto Quesada". En torno al criollismo. Textos y polémicas. Comp. Alfredo Rubione. Buenos Aires, Centro Editor de América Latina, 1983, pp. 236-37.

Chartier, Roger. "Materialidad del texto, textualidad del libro". Orbis Tertius, no. 12, 2006, pp. 1-15.

Darnton, Robert. El beso de Lamourette: reflexiones sobre historia cultural. Trad. Antonio Saborit. Buenos Aires, Fondo de Cultura Económica, 2011.

Duncan, Tim. "La prensa política: Sud América, 1884-1892". La Argentina del ochenta al centenario. Comps. Gustavo Ferrari y Ezequiel Gallo. Buenos Aires, Sudamericana, 1980, pp. 761-783.

Espósito, Fabio. La emergencia de la novela argentina. La prensa, los lectores y la ciudad (1880-1890). La Plata, Ediciones al margen, 2006.

Espósito, Fabio, García Orsi, Ana, Schinca, Germán y Sesnich, Laura. El naturalismo en la prensa porteña. Reseñas y polémicas so- 
bre la formación de la novela nacional (1880-1892). La Plata, Universidad Nacional de La Plata, 2011.

Gálvez, Manuel. Recuerdos de la vida literaria I. Amigos y maestros de mi juventud. En el mundo de los seres ficticios. Buenos Aires, Taurus, 2002.

García Mérou, Martín. Carta a Miguel Cané. Madrid, 1885.

Goldchluk, Graciela. "El archivo como política de lectura: aportes de la crítica genética". Actas Primeras Jornadas de reflexión sobre la construcción del archivo. Comps. Karina Janello y Marcela Frías. Buenos Aires, Centro de Documentación e Investigación de la Cultura de Izquierdas, CeDInCI-Universidad Nacional de San Martin, UNSAM, 2016, pp., 52-64.

Hay, Louis. "La escritura viva". Trad. María Inés Palleiro. Filología, no. 37, 1994, pp. 5-22.

Laera, Alejandra. El tiempo vacío de la ficción. Las novelas argentinas de Eduardo Gutiérrez y Eugenio Cambaceres. Buenos Aires, Fondo de Cultura Económica, 2004.

Nouzielles, Gabriela. Ficciones somáticas. Naturalismo, nacionalismo y políticas médicas del cuerpo (Argentina 1880-1910). Rosario, Beatriz Viterbo, 2000.

Pastormerlo, Sergio. "Miguel Cané. Éxitos y fracasos de una trayectoria y un final". Historia crítica de la literatura argentina. Volumen 3. El brote de los géneros. Dir. General Noé Jitrik, Dir. del volumen, Alejandra Laera. Buenos Aires, Emecé, 2010, pp. 257-276.

“Novela, mercado y succès de scandale en Argentina, 18801890". Estudios, no. 15, 2007, pp.17-28.

Ramos, Julio. Desencuentros de la modernidad en América Latina. Literatura y política en el siglo XIX. Caracas, Fundación Editorial El perro y la rana, 2009.

Rancière, Jacques. El hilo perdido. Ensayos sobre la ficción moderna. Trad. María del Carmen Rodríguez. Buenos Aires, Manantial, 2015.

Rojas, Ricardo. Historia de la literatura argentina. II. Los modernos. Buenos Aires, Librería La Facultad, 1922.

Saferstein, Ezequiel Andrés. "Entre los estudios sobre el libro y la edición: el 'giro material' en la historia intelectual y la sociología". Información, Cultura y Sociedad, no. 29, 2013, pp. 139-166. 
Sommer, Doris. Ficciones fundacionales. Las novelas nacionales en América Latina. Trad. José Leandro Urbina y Ángela Pérez. Bogotá, Fondo de Cultura Económica, 2004.

Viñas, David. Literatura argentina y realidad política. Buenos Aires, Jorge Álvarez, 1964. 